\title{
Konstitusionalitas Pengelolaan Migas dalam Mewujudkan Kedaulatan Energi Indonesia
}

\begin{tabular}{|c|c|}
\hline \multicolumn{2}{|c|}{$\begin{array}{l}\text { Fatma Ulfatun Najicha } \\
\text { Faculty of Law, Universitas Sebelas Maret, surakarta, Indonesia }\end{array}$} \\
\hline Info Artikel & Abstract \\
\hline $\begin{array}{l}\text { Keywords: } \\
\text { Oil and Gas; Kesejahtraan; } \\
\text { Constitution; Justice. }\end{array}$ & $\begin{array}{l}\text { This study aims to explain and analyze constitutional oil and gas governance } \\
\text { in the context of creating the welfare of the Indonesian people. This research } \\
\text { is a normative study, using secondary data in the form of primary, secondary } \\
\text { and tertiary legal materials. The results of the study found that the } \\
\text { constitutionality of Indonesian oil and gas management is regulated and } \\
\text { contained in the oil and gas laws and regulations which give Pertamina a dual } \\
\text { function as operator and regulator, while the policy function is carried out by } \\
\text { the government. This management violates the constitution and the principle } \\
\text { of state control or state sovereignty over oil and gas as stipulated in the } 1945 \\
\text { Constitution which is then spelled out in statutory regulations in the oil and } \\
\text { gas sector. Another finding is that the management of oil and gas in Indonesia } \\
\text { is still unable to have a positive impact on the Indonesian people and is } \\
\text { detrimental to state finances. The current management is very dominated by } \\
\text { foreign parties because the Indonesian oil and gas sector is controlled by } \\
\text { foreign companies up to } 89 \text { percent or the potential for state financial losses } \\
\text { due to the imposition of "cost recovery" in the oil and gas sector that is not } \\
\text { exactly Rp 345,996 trillion rupiah per year or } 1.7 \text { billion per day. }\end{array}$ \\
\hline & Abstrak \\
\hline $\begin{array}{l}\text { Kata kunci: } \\
\text { Migas; Kesejahtraan; } \\
\text { Konstitusi; Keadilan. } \\
\text { Corresponding Author: } \\
\text { Fatma Ulfatun Najicha, E-mail: } \\
\text { fatmanajicha_law@staff.uns.ac.id }\end{array}$ & $\begin{array}{l}\text { Penelitian ini bertujuan untuk menjelaskan dan menganalisa tata } \\
\text { kelola migas yang konstitusional dalam rangka menciptakan } \\
\text { kesejahtraan rakyat Indonesia. Penelitian ini merupakan penelitian } \\
\text { normatif, dengan menggunakan data sekunder berupa bahan hukum } \\
\text { primer, sekunder dan tersier. Hasil penelitian menemukan baha } \\
\text { konstitusionalitas pengelolaan migas Indonesia diatur dan } \\
\text { dituangkan dalam peraturan perundang-undangan migas yang } \\
\text { memberikan fungsi ganda kepada Pertamina sebagai operator dan } \\
\text { regulator, sedangkan fungsi kebijakan dijalankan oleh pemerintah. } \\
\text { Pengelolaan tersebut melanggar konstitusi dan prinsip penguasaan } \\
\text { negara atau kedaulatan negara atas migas sebagaimana ditetapkan } \\
\text { dalam UUD } 1945 \text { kemudian dijabarkan dalam peraturan perundang- } \\
\text { undangan di bidang migas. Temuan lain adalah pengelolaan migas di } \\
\text { Indonesia, masih belum mampu memberikan dampak positif bagi } \\
\text { rakyat Indonesia dan merugikan keuangan negara. Pengelolaan saat } \\
\text { ini sangat didominasi pihak asing karena dunia permigasan Indonesia } \\
\text { dikuasai oleh perusahaan asing sampai } 89 \text { persen atau potensi } \\
\text { kerugian keuangan negara akibat pembebanan "cost recovery" sektor } \\
\text { migas yang tidak tepat mencapai Rp } 345,996 \text { Triliun rupiah per tahun } \\
\text { atau 1,7 milliar tiap hari. }\end{array}$ \\
\hline
\end{tabular}




\section{Pendahuluan}

Indonesia sangat bergantung kepada Minyak dan Gas Bumi. Realitas yang ada tidak dapat dipungkiri bahwa Indonesia sangat bergantung kepada Sumber Daya Alam Minyak dan Gas Bumi. Berdasarkan Data dari Pertamina untuk tahun 2013 tercatat bahwa total Kebutuhan Nasional untuk Minyak Bumi adalah sebesar 77,00 juta KL, sementara kemampuan produksi kilang nasional hanya 38,10 juta KL sehingga pada tahun 2013 tercatat defisit kebutuhan 38,9 juta KL atau sekitar 51\%.1 Gap kebutuhan minyak dengan kemampuan produksi ini diperkirakan akan cenderung stabil atau bahkan mengalami peningkatan jika tidak segera diambil langkah-langkah penyelematannya. Kondisi ini diperberat dengan adanya fakta bahwa performa cadangan dan produksi minyak bumi relatif menurun sejak puncak produksi minyak Indonesia ke-2, sehingga sehingga dengan asumsi tidak ada penemuan cadangan minyak bumi, maka usia minyak bumi Indonesia hanya sekitar 12 tahun (berdasarkan cadangan terbukti). ${ }^{2}$

Akan tetapi, kondisi yang demikian itu, belum merubahn mindset bahwa kondisi cadangan minyak Indonesia saat ini berbeda dengan cadangan minyak pada era dulu yang relatif cukup berlimpah, sehingga Indonesia pernah mengalami booming pada tahun 1977 sampai tahun 2000. Dengan kapasitas produksi mencapai 1.6 juta MBOPD. ${ }^{3}$ Namun setelah itu tingkat produksi Indonesia cenderung menurun hingga Indonesia memilih keluar keluar dari Organization of the Petroleum Exporting Countries (OPEC) dengan status suspended sejak Januari 2009. Tingginya ketergantungan Indonesia akan minyak bumi tersebut menunjukkan bahwa energi yang berupa minyak bumi adalah vital dan pembenahan tata kelola minyak bumi menjadi hal yang urgent untuk dilakukan dalam rangka menciptakan kedaulatan energi di Indonesia. Saat ini di Indonesia regulasi yang mengatur mengenai pengelolaan minyak bumi adalah Undang-undang Nomor 22 Tahun 2001 tentang Minyak dan Gas Bumi (UU Migas). Selain menjadi payung hukum dalam pengelolaan minyak bumi UU Migas juga mengatur pengelolaan gas bumi. ${ }^{4}$

${ }^{1}$ A K Jaelani, 'Politik Hukum Putusan Mahkamah Konstitusi Nomor 36/PUU-X/2012 Tentang Pembubaran BP MIGAS: Upaya Mengembalikan Kedaulatan Negara Menuju ...', Jurnal Panggung Hukum, $1.1 \quad$ (2015) <https://www.aifisdigilib.com/uploads/1/3/4/6/13465004/isi._3._politik_hukum_putusan_mahkamah_konstitu si_(penulis_aqj).pdf $>$.

${ }^{2}$ Eni Muryani, 'Sinergisitas Penegakan Hukum Pada Kasus Pertambangan Emas Tanpa Izin $\begin{array}{llllll}\text { Di Kabupaten Banyumas, Jawa Tengah', Bestuur, } 7.2 & \text { (2019), } 19\end{array}$ <https://doi.org/10.20961/ bestuur.v7i2.40437>.

${ }^{3}$ Willy Naresta Hanum, 'Setting of Earth Oil Management in Old Wells Based on the Principle Social Justice', Bestuur, 8.2 (2020), 70 <https:// doi.org/10.20961/bestuur.v8i2.42789>.

${ }^{4}$ Nizammudin Nizammudin, 'HAK MENGUASAI NEGARA DALAM SISTEM TATA KELOLA MINYAK DAN GAS BUMI: ANALISIS PUTUSAN MAHKAMAH KONSTITUSI NOMOR 36/PUU-X/2012 / The State Control Rights In Oil And Gas Management System: The 
Selama hampir 15 tahun berlaku sejak diundangkan pada tanggal 23 November 2001, UU Migas telah mengalami 4 kali pengujian di Mahkamah Konstitusi karena didalamnya terdapat pasal-pasal yang dianggap bertentangan dengan konstitusi Indonesia (UUD 1945) khususnya terkait Pasal 33 ayat (2) dan ayat (3) UUD Tahun 1945, meskipun terdapat pula satu perkara yang dinyatakan tidak dapat diterima dikarenakan persoalan legal standing. Dalam 3 (tiga) kali judicial review yang setidaknya ada 16 pasal dari UU tersebut yang dibatalkan oleh Mahkamah Konstitusi, yaitu melalui Putusan Mahkamah Konstitusi Nomor 002/PUU-I/2003/ sebanyak 3 (tiga) pasal dan Putusan Mahkmah Konstitusi Nomor 36/PUU-X/2012 sebanyak 13 (tigabelas). ${ }^{5}$

Secara garis besar materi yang dibatalkan melalui putusan Mahkamah Konstitusi tersebut terkait dengan: Pertama, Persoalan kelembagaan yang diatur di dalamnya, yang membuat kekuasaan pemerintah justru menjadi terbagi-bagi dan menjadi tidak efektif, tidak jarang juga terjadi overlapping kewenangan di antara lembaga-lembaga tersebut. Beberapa lembaga yang ada pada UU MIGAS adalah Kementerian Energi dan Sumber Daya Mineral (ESDM), Badan Pelaksana Minyak dan Gas Bumi (BP Migas), Badan Pengatur Kegiatan Hilir (BPH Migas) dan Pertamina. Persoalan ini menjadi semakin gawat ketika BP Migas yang didudukan sebagai Badan Pelaksana justru dinyatakan inskontitusional oleh Mahkamah Konstitusi. ${ }^{6}$ Kedudukan BP Migas pasca keputusan MK tersebut kemudian digantikan oleh Satuan Kerja Khusus Pelaksana Kegiatan Usaha Hulu Minyak dan Gas Bumi (SKK Migas), namun kehadiran SKK Migas ini oleh banyak pihak dirasa masih belum efektif yang terlihat dari penurunan lifting minyak domestik yang terjadi. Kedua, Persoalan kontrak dalam UU MIGAS.7

Kontrak-kontrak yang mengacu pada UU MIGAS seolah-olah memiliki kekebalan terhadap perubahan legislasi yang terjadi di Indonesia. Implikasi terhadap hal tersebut bahwa perubahan legislasi yang ada tidak bisa mempengaruhi kontrak-kontrak yang telah terjadi. Konsekuensinya bahwa

Analysis Of Constitutional Decision No 36/PUU-X/2012', Jurnal Hukum Dan Peradilan, 5.3 (2016), $407<$ https://doi.org/10.25216/jhp.5.3.2016.407-430>.

${ }^{5}$ Fatma Ulfatun Najicha, I Gusti Ayu Ketut Rachmi Handayani, and Hartiwiningsih, 'Legal Protection "Substantive Rights for Environmental Quality" on Environmental Law Against Human Rights in the Constitution in Indonesia', 140.Icleh (2020), 719-24 <https://doi.org/10.2991/aebmr.k.200513.136>.

${ }^{6}$ I.G.A.K. Rachmi Handayani, Lego Karjoko, and Abdul Kadir Jaelani, 'Model Pelaksanaan Putusan Mahkamah Konstitusi Yang Eksekutabilitas Dalam Pengujian Peraturan Perundang$\begin{array}{llllll}\text { Undangan Di } \quad \text { Indonesia', } & \text { Bestuur, } & 7.1 & \text { (2019), }\end{array}$ $<$ https://jurnal.uns.ac.id/bestuur/article/view/42700>.

7I Dewa Made Suartha, 'Criminal Policy Formulation on Regulation of Death Penalties for Criminal Actors', Journal of Morality and Legal Culture, 1.1 (2020), 12 <https://doi.org/10.20961/jmail.v1i1.44743>. 
pemerintah harus menunggu jangka waktu kontrak tersebut habis untuk dapat melakukan tindakan penyesuaian. Hal ini menjadi persoalan tersendiri mengingat masa kontrak kerja sama sebagaimana diamanatkan UU MIGAS cukup lama yaitu paling lama 30 (tiga puluh) tahun dan dapat diperpanjang paling lama 20 (duapuluh) tahun yang kontrak itu terdiri atas jangka waktu eksplorasi maupun eksploitasi. Mengacu pada kondisi-kondisi yang telah diuraikan dalam latar belakang diatas, makapenyesuaian tata kelola Migas di Indonesia sebagai konsekuensi dan adaptasi atas: 8

1. Perubahan cadangan, kemampuan penyediaan dan kebutuhann Migas di Indonesia; dan

2. Pembatalan beberapa ketentuan vital dalam UU Migas 22 Tahun 2001 oleh MahkamahKonstitusi,

Oleh karena itu adalah sesuatu yang urgent untuk segera dilakukan melalui pembaharuan UU Migas No. 22 Tahun 2001, akan tetapi sebagai langkah awal menuju pembaharuan UU Migas tersebut dan mengacu pada Pasal 19 UU Nomor 12 Tahun 2011 Tentang Pembentukan Peraturan Perundangundangan, perlu diketahui rambu-rambu konstitusional berkenaan dengan perumusan hukum tata kelola migas di masa depan. Tulisan ini di maksudkan penulis untuk memberikan konsepsi desain konstitusional tata kelola migas melalui UU Migas yang baru dengan menggunakan Putusan-Putusan MK terdahulu sebagai cetak biru hukum migas Indonesia di masa depan.

\section{Metode Penelitian}

Jenis penelitian yang digunakan dalam menyusun penelitian ini adalah penelitian hukum normatif. Penelitian hukum normatif lebih mengutamakan studi pustaka (library research). Penelitian ini bersifat deskriptif, yakni mendeskripsikan dan menganalisis konstitusionalitas pengelolaan migas dalam mewujudkan kedaulatan migas di Indonesi. ${ }^{9}$ Penelitian ini menggunakan an data sekunder. Data sekunder merupakan bahan hukum dalam penelitian yang diambil dari studi kepustakaan yang terdiri dari bahan hukum primer, bahan hukum sekunder dan bahan non hukum. Data Sekunder diperoleh dengan studi dokumentasi dan penelusuran literatur yang berkaitan dengan pelaksanaan perlindungan tanah ulayat dan teori yang mendukungnya. Sumber data yang digunakan dalam penelitian ini adalah sumber data sekunder, yakni sumber data

${ }^{8}$ Cut Asmaul Husna, 'Strategi Penguatan Pengelolaan Bersama Minyak Dan Gas Bumi Di Wilayah Laut Strengthened Strategy of Joint Management Oil and Gas in The', Jurnal Konstitusi, 15.1 (2018).

9I. Gusti Ayu Ketut Rachmi Handayani and others, 'Environmental Management Strategy in Mining Activities in Forest Area Accordance with the Based Justice in Indonesia', Journal of Legal, Ethical and Regulatory Issues, 21.2 (2018). 
yang bersifat pribadi dan bersifat publik. Analisis data yang digunakan dalam penelitian ini adalah analisis kualitatif yang kemudian disajikan dalam bentuk deskriptif. ${ }^{10}$

\section{III.Pembahasan}

Posisi UUD 1945 sebagai hukum dasar memberikan legal consequence bahwa setiap materi peraturan perundang-undangan yang berada di bawahnya tidak boleh bertentangan dengan materi-materi yang terdapat dalam UUD 1945. UUD 1945 yang menentukan garis besar, arah, isi dan bentuk hukum yang akan diberlakukan di Indonesia, termasuk arah kebijakan hukum dan politik hukum minyak dan gas bumi di Indonesia. Amandemen yang dilakukan pada tahun 2001 terhadap Pasal 33 UUD 1945 memuat dua tambahan pasal dan judul bab, yaitu terletak pada BAB XIV Batang Tubuh UUD 1945 dengan judul bab Perekonomian Nasional dan Kesejahteraan Sosial dengan memuat 5 ayat. ${ }^{11}$

Menurut Kwik Kian Gie, amandemen yang dilakukan terhadap Pasal 33 UUD 1945 tersebut berkaitan dengan liberalisasi di sektor pengelolaan sumber daya alam. Rakyat yang sangat membutuhkan terpaksa harus membayar dengan harga tinggi, tidak ada lagi kewajiban negara dalam hal ini pemerintah untuk mengadakan secara gotong royong melalui instrumen pajak. Hal tersebut terjadi karena adanya perubahan orientasi hukum dimana yang berkembang adalah mekanisme pasar sempurna, liberalisasi, swastanisasi dan globalisasi. Bagaimanapun secara perlahan hal ini akan meminggirkan elaborasi gagasan nasionalisme dan patriotisme. ${ }^{12}$

Kemakmuran dan kesejahteraan yang dicita-citakan semakin jauh dari harapan, liberalisasi dan mekanisme pasar telah diberlakukan sedemikian jauh dan melanggar pasal 33 UUD 1945. Demam liberalisasi yang menjelma dalam produk perundang-undangan di Indonesia merupakan pelaksanaan dari agenda-agenda ekonomi neoliberal yang telah dimulai sejak pertengahan 1980an, antara lain melalui paket kebijakan liberalisasi, deregulasi, dan debirokratisasi. Namun, implementasinya secara massif menemukan momentumnya setelah Indonesia dilanda krisis ekonomi yang parah dan mengundang lembaga seperti IMF untuk memulihkan perekonomian nasional. Sebagai syarat untuk pencairan dana pinjaman, pemerintah Indonesia wajib

${ }^{10}$ L Kajoko, Zaidah Nur Rosidah, and I.G.A.K. Rachmi Handayani, 'Refleksi Paradigma Ilmu Pengetahuan Bagi Pembangunan Hukum Pengadaan Tanah', Bestuur, 7.1 (2019), 1-14 <https://jurnal.uns.ac.id/bestuur/article/view/42694>.

11Pane Erina and Adam Muhammad Yanis, 'Reconstruction of Mining Policies on Justice in Lampung Province', Bestuur, 8.2 (2020), 139 <https:/ / doi.org/10.20961/bestuur.v8i2.42830>.

12 Waluyo, F. Ulfatun Najicha, and Sapto Hermawan, 'Law in the Globalization and Its Influence on Economic Development and Environmental Preservation Based on Pancasila and the Indonesian Constitution of 1945', 358.Icglow (2019), 317-21 <https://doi.org/10.2991/icglow-19.2019.78>. 
melaksanakan program-program penyesuaian struktural (structural adjustment program) melalui penandatanganan Letter of Intent (LOI), yang salah satu butir kesepakatannya adalah liberalisasi tata kelola sektor-sektor strategis di bidang sumber daya alam. ${ }^{13}$

Akibat yang paling nampak adalah Ketika sejumlah undang- undang yang berkaitan erat dengan Pasal 33 UUD 1945 hendak disahkan dalam Sidang Paripurna DPR pada masa transisi demokrasi, beberapa anggota dewan dari beberapa fraksi mengajukan minderheidsnota (nota keberatan), dengan alasan substansi sejumlah undang- undang itu bernisbat pada paham liberal yang 'durhaka' terhadap UUD 1945, khususnya pasal 33 yang mengatur soal perekonomian nasional. ${ }^{14}$ Kendatipun disertai minderheidsnota, secara material sejumlah UU tersebut sah sebagai undang- undang sejak disahkan DPR dan sah secara formal setelah ditandatangani Presiden. Secara hukum, minderheidsnota tidak menghalangi atau membatalkan sebuah persetujuan yang disahkan oleh kuorurm Undang- undang yang pengesahannya disertai minderheidsnota itu kemudian diajukan uji materi (Judicial review) oleh sejumlah kalangan ke Mahkamah Konstitusi (MK). Dari sejumlah undang-undang yang disebutkan di atas, hanya satu yang secara mutlak dibatalkan MK, yaitu UU No 20 Tahun 2002 tentang Ketenagalistrikan. ${ }^{15}$

Menurut Subianto Tjakrawerdaja, pengelolaan minyak dan gas bumi berdasarkan Pasal 33 UUD 1945 harus memuat tujuh ciri konstitusional, yaitu: Pertama, perekonomian bertujuan untuk mencapai kemakmuran bersama seluruh rakyat, hal ini secara eksplisit dijelaskan dalam penjelasan Pasal 33 UUD 1945. Kedua, keikutsertaan rakyat dalam pemilikan, proses produksi dan menikmati hasilnya. Hal ini sesuai dengan rumusan yang terdapat dalam Pasal 33 ayat (1) dan ayat (4) UUD 1945. Ketiga, sesuai dengan prinsip Pasal 33 ayat (4) UUD 1945 yaitu efisiensi berkeadilan, perekonomian perlu dijalankan dengan menggunakan mekanisme pasar yang berkeadilan yang didasarkan pada persaingan yang sehat dan peranan serta kewenangan negara untuk intervensi jika terjadi kegagalan pasar. ${ }^{16}$

Keempat, peran Negara harus dijamin, sebagaimana diamanatkan Pasal 33 ayat dan ayat (3) UUD 1945 terutama dalam hal perencanaan ekonomi nasional,

${ }^{13}$ Fatma Ulfatun Najicha, 'Water Availability in the Framework of Environmental Justice: Reconstruction of Municipal Waterworks (Pdam) Regulations', 20.4 (2019), 51-55.

${ }^{14} \mathrm{M}$. Ilham F. Putuhena, 'POLITIK HUKUM PENGELOLAAN HULU MIGAS PASCA PUTUSAN MAHKAMAH KONSTITUSI (Politics of Law of Upstream Oil and Gas Management after the Constitutional Court Decision)', Jurnal Rechts Vinding, 4.2 (2015), 237-53 <http://rechtsvinding.bphn.go.id/artikel/ART 4 JRV 4.2 WATER.pdf>.

${ }^{15}$ Cut Asmaul Husna TR, 'Strategi Penguatan Pengelolaan Bersama Minyak Dan Gas Bumi Di Wilayah Laut', Jurnal Konstitusi, 15.1 (2018), 140 <https://doi.org/10.31078/jk1517>.

${ }^{16} \mathrm{E}$. Hambali and M. Rivai, 'The Potential of Palm Oil Waste Biomass in Indonesia in 2020 and 2030', IOP Conference Series: Earth and Environmental Science, 65.1 (2017) <https://doi.org/10.1088/1755-1315/65/1/012050>. 
dalam membentuk dan menegakkan pelaksanaan undang-undang, dan dalam hal melaksanakan program pelayanan dan pemberdayaan masyarakat, pembebasan pajak, pemberian subsidi dan lainnya. Kelima, BUMN sebagai salah satu soko guru kegiatan ekonomi menguasai cabang-cabang produksi yang penting dan yang menguasai hajat hidup orang banyak. Ini jelas tertuang dalam Pasal 33 ayat UUD 1945. Keenam, koperasi sebagai soko guru perekonomian rakyat harus diwujudkan dalam semangat kebersamaan dengan BUMN dan swasta, serta sebagai badan usaha ekonomi rakyat. Ketujuh, perekonomian nasional haruslah merupakan perwuju dan dari kemitraan yang sejajar antara koperasi, BUMN dan swasta. Prinsip ini termuat dalam Pasal 33 ayat (1) UUD 1945.17

Ciri-ciri konstitusional inilah yang semestinya diterjemahkan dalam seluruh rangkaian peraturan perundang- undangan pengelolaan minyak dan gas bumi. ${ }^{14}$ Sebesar-besarnya kemakmuran rakyat merupakan tujuan dari setiap pengelolaan dan penggunaan sumber daya alam nasional. Tujuan ini dipandang sebagai kepentingan yang tidak dapat diabaikan, sebab selain merupakan amanat konstitusi, juga didambakan oleh setiap warga Negara dan menjadi tanggung jawab negara sebagai konsekuensi dari hak menguasai negara itu sendiri. Oleh karena itu setiap pengusahaan dan penggunaan sumber daya alam disesuaikan dengan tujuan (doelmatig). ${ }^{18}$

Sifat kesesuaian dengan tujuan dari pengusahaan dan penggunaan sumber daya alam adalah mutlak dan tidak dapat diubah. Namun, hal tersebut tidak berarti merupakan tujuan dari hukum. ${ }^{19}$ Tujuan dari hukum antara lain adalah adanya kepastian hukum terhadap sifat mutlak dan tidak dapat diubah tersebut. Dalam arti inilah kesesuaian hukum (rehtmatigheid) diletakkan pada pengusahaan dan penggunaan sumber daya alam untuk sebesar-besarnya kemakmuran rakyat. Kemakmuran rakyat merupakan cita negara kesejahteraan yang harus diwujudkan oleh negara dan pemerintah Indonesia. ${ }^{20}$ Hak menguasai oleh negara atas bumi, air dan kekayaan alam yang terkandung di dalamnya pada hakekatnya merupakan suatu perlindungan dan jaminan akan terwujudnya sebesar besarnya kemakmuran rakyat. Tetapi apabila hak menguasai oleh negara bergeser dari beheersdaad menjadi eigensdaad maka tidak ada jaminan

\footnotetext{
${ }^{17}$ Suwari Akhmaddhian, 'Discourse on Creating a Special Environmental Court in Indonesia to Resolve Environmental Disputes', Bestuur, $8.2 \quad$ (2020), 129 <https:/ / doi.org/10.20961/bestuur.v8i2.42774>.

18Muryani.

${ }^{19}$ Ronald Z. Titahelu, Penetapan Azas-azas Hukum Umum dalam Penggunaan Tanah untuk Sebesar-besar Kemakmuran Rakyat, (Surabaya: Disertasi Program Pasca Sarjana pada Universitas Airlangga, 1993) h. 14.

${ }^{20}$ Ibid.
} 
hak menguasai oleh negara penggunaan objek sumber daya alamnya dipergunakan untuk sebesar besarnya kemakmuran rakyat. ${ }^{21}$

Oleh karena itu, Mahkamah Konstitusi yang telah menerima, 4 (empat) kali menerima permohonan judicial review UU Migas baik terkait keseluruhan pasal maupun beberapa pasal yang dimohonkan uji materi. Permohonan uji materi pertama diterima MK pada 15 Oktober 2003, diputus pada 21 Desember 2004. Permohonan uji materi kedua diajukan pada 10 April 2007, diputus pada 13 Desember 2007. Putusan uji materi kedua belum masuk ke pokok perkara karena legal standing pemohon tidak diterima (niet ontvankelijk verklaard). Permohonan uji materi ketiga diajukan 29 Maret 2012, diputus pada 5 November 2012. Permohonan uji materi keempat diajukan pada 22 Juni 2012, diputus pada 26 Maret 2013. Beberapa pokok putusan MK memberikan rambu-rambu konstitusional berkenaan dengan pengelolaan hukum pengelolaan Migas. ${ }^{22}$

Selain itu perlu juga direkomendasikan agar Indonesia dapat mempertimbangkan semacam versi dari "pengistimewaan". Ini akan memberi Pertamina peluang yang lebih luas untuk mengembangkan berbagai proyek dibandingkan dengan yang dimiliki tahun-tahun belakangan ini, serta akan memberikan insentif untuk menjadi sebuah perusahaan komersil yang lebih dinamis dan berdaya-saing. Pilihan ini juga akan mengurangi risiko bagi investasi swasta atau menciptakan inefisiensi dengan memandatkan Pertamina untuk memainkan peran dominan di dalam setiap proyek. ${ }^{23}$

Indonesia perlu memutuskan lembaga mana yang secara prinsip bertanggungjawab atas peraturan dan pengawasan kegiatan di hulu. Tampaknya saat ini ada dua opsi utama, yakni untuk memberikan tanggungjawab pengaturan kepada Pertamina (yang disebut pendekatan "dua-pilar" di mana Pertamina memainkan peran pengawasan dan implementasi sehari-hari, di bawah pengawasan yang lebih luas dari Kementrian Energi dan Sumber Daya Mineral), atau untuk mengamanahkan tanggungjawab itu kepada satu badan usaha milik negara yang baru (BUMN Khusus), yang bakal mengambilalihbanyak fungsi yang semula dilaksanakan oleh BP Migas (atau dikenal sebagai "pendekatan tiga pilar"). ${ }^{24}$

${ }^{21}$ Erina and Yanis.

${ }^{22}$ Martin Roestamy, 'Model Land Supply For Land Bank To House Application', Bestuur, 8.1 (2020), 27-39.

${ }^{23}$ Lego Karjoko, 'Setting of Plantation Land Area Limitation Based on Social Function Principles of Land Cultivation Rights To Realize Social Welfare-Promoting Plantation', Jurnal Dinamika Hukum, 17.1 (2017), 1 <https:/ / doi.org/10.20884/1.jdh.2017.17.1.606>.

${ }^{24}$ Hasfarm D. Purba, Christia Meidiana, and Dimas W. Adrianto, 'Waste Management Scenario through Community Based Waste Bank: A Case Study of Kepanjen District, Malang Regency, Indonesia', International Journal of Environmental Science and Development, 5.2 (2014), 212$16<$ https:// doi.org/10.7763/ijesd.2014.v5.480>. 


\section{Skema 1}

Model Pola Kelembagaan dalam Pengelolan Migas

\begin{tabular}{|c|c|}
\hline \multicolumn{2}{|c|}{$\begin{array}{c}\text { Pola Tiga Pilar } \\
\text { kelembagaan }\end{array}$} \\
\hline \multicolumn{1}{|c|}{$\begin{array}{c}\text { Pertamina } \\
\text { Khusus Aktifitas } \\
\text { Komersial }\end{array}$} \\
\hline & $\begin{array}{c}\text { BUMN Khusus } \\
\text { Pengawasan } \\
\text { terhadap } \\
\text { Kontrak kerjasama } \\
\text { (KKS) }\end{array}$ \\
\hline & $\begin{array}{c}\text { Kementerian } \\
\text { Penyusunan } \\
\text { Strategi Sektor } \\
\text { secara } \\
\text { Komprehensif }\end{array}$ \\
\hline
\end{tabular}

\begin{tabular}{|c|c|}
\hline \multicolumn{2}{|c|}{$\begin{array}{c}\text { Pola Dua Pilar } \\
\text { kelembagaan }\end{array}$} \\
\hline \multicolumn{1}{|c|}{$\begin{array}{c}\text { Pertamina } \\
\text { Tanggungjawab } \\
\text { komersil dan } \\
\text { fungsi } \\
\text { pengaturan/ } \\
\text { pengawan }\end{array}$} \\
\hline & $\begin{array}{c}\text { Kementerian } \\
\text { Penyusunan } \\
\text { Strategi } \\
\text { sektor secara } \\
\text { komprehensi }\end{array}$ \\
\hline
\end{tabular}

Berbagai versi dari sistem-sistem ini telah dilembagakan di negara produsen minyak lain dengan hasil bermacam-macam. Dari beberapa putusan MK tersebut dapat ditarik sejumlah benang merah sebagai berikut. Pertama, putusan MK Nomor 002/PUU-I/2003 dan putusan MK Nomor 36/PUU-X/2012 sama-sama menghendaki penguatan penguasaan negara di sektor hulu dan memperbolehkan persaingan di sektor hilir. Sistem unbundling, yang membuka kompetisi di bisnis pengolahan, pengangkutan, penyimpanan, dan niaga dinyatakan tidak bertentangan dengan konstitusi. ${ }^{25}$

Hal ini juga dikuatkan dengan Putusan MK Nomor 65/PUU-X/2012 yang menolak membubarkan BPH Migas sebagai institusi pemerintah yang mengatur sektor hilir. Dikuatkannya posisi BPH Migas sebagai Badan Pengatur, artinya di sektor hilir, MK membenarkan fungsi pemerintah sebagai regulator, tidak harus menjadi operator. ${ }^{26}$ Adapun di sektor hulu, dibandingkan putusan MK Nomor 002/PUU-I/2003, putusan MK Nomor 36/PUU-X/2012 memberikan tafsir penguasaan negara lebih radikal dengan membatalkan model tata kelola tiga kaki yang mengesampingkan kewenangan Negara c.q. Perusahaan Negara untuk bertindak langsung menjadi operator. Di sektor eksplorasi dan eksploitasi, negara

${ }^{25}$ Y. Arizona, 'Perkembangan Konstitusionalitas Penguasaan Negara Atas Sumber Daya Alam Dalam Putusan Mahkamah Konstitusi', Jurnal Konstitusi, 8.3 (2011), 257-314.

${ }^{26}$ Munawar Kholil, ‘Waste to Energy Technology_ The Potenti...1 Waste in Indonesia _ Enhanced Reader.Pdf'. 
harus dapat bertindak bukan hanya sebagai regulator tetapi juga operator.Kedua, putusan MK Nomor 002/PUU-I/2003 dan putusan MK Nomor 36/PUU-X/2012 sama-sama menghendaki penguatan BUMN sebagai pemegang lisensi atau Kuasa Pertambangan untuk mengelola sektor hulu dan berperan vital di sektor hilir migas. Putusan MK Nomor 002/ PUU-I/2003 menegaskan Kuasa Pertambangan tidak dapat diserahkan langsung kepada pelaku usaha (BU/BUT). ${ }^{27}$

\section{Penutup}

Putusan MK Nomor 36/PUU-X/2012 melarang kontrak hulu berpola G2B karena mendegradasi kedaulatan negara. Kontrak seharusnya dilakukan berpola B2B antara BUMN dengan pelaku usaha (B2B). Kontrak berpola B2B akan semakin mengukuhkan bahwa KKS bukan perjanjian internasional yang butuh persetujuan DPR. Ketiga, MK menghendaki iklim investasi migas kondusif dengan mengadopsi sistem perpajakan khusus. Sistem yang dikembangkan UU Migas mencabut asas lex specialis dalam sistem fiskal migas. Akibatnya, pungutan dilakukan sejak periode eksplorasi hingga produksi. Pungutan pajak pra-produksi tidak adil dan merusak iklim investasi hulu migas yang, pada gilirannya, menghambat kesempatan mencapai sebesar-besar kemakmuran rakyat. Keempat, MK melarang liberalisasi total harga BBM/BBG untuk diserahkan sepenuhnya kepada mekanisme pasar. Kebijakan harga BBM/BBG harus ditetapkan pemerintah dengan mempertimbangkan banyak hal, termasuk acuan pasar. Kelima, MK menghendaki pemanfaatan hasil eksplorasi dan eksploitasi migas untuk optimalisasi kebutuhan domestik. Dalam putusan MK Nomor 002/PUU-I/2003, MK mengoreksi ketentuan DMO yang tidak mencerminkan visi menjamin security of supply. Lima hal ini merupakan kerangka acuan penyusunan disain tata kelola dan sistem pengusahaan migas yang konstitusional. Mengikuti acuan konstitusi sebagaimana dijabarkan MK akan membuat regulasi baru yang dibentuk relatif aman dari gugatan uji materi yang tidak berkesudahan.

\section{Refrences}

Akhmaddhian, Suwari, 'Discourse on Creating a Special Environmental Court in Indonesia to Resolve Environmental Disputes', Bestuur, 8.2 (2020), 129 <https:/ / doi.org/10.20961/bestuur.v8i2.42774>

Arizona, Y., 'Perkembangan Konstitusionalitas Penguasaan Negara Atas Sumber Daya Alam Dalam Putusan Mahkamah Konstitusi', Jurnal Konstitusi, 8.3 (2011), 257-314

Erina, Pane, and Adam Muhammad Yanis, 'Reconstruction of Mining Policies on

${ }^{27}$ Rudy Iskandar Ichlas, 'Questioning the Independence of Media Coverage in the 2019 Elections', Jurnal Bestuur, 8.1 (2020) <https:/ / doi.org/10.20961/ bestuur.42725>.

Fatma Ulfatun Najicha: Konstitusionalitas Pengelolaan Migas...... 
Justice in Lampung Province', Bestuur, 8.2 (2020), 139 <https://doi.org/10.20961/bestuur.v8i2.42830>

Hambali, E., and M. Rivai, 'The Potential of Palm Oil Waste Biomass in Indonesia in 2020 and 2030', IOP Conference Series: Earth and Environmental Science, 65.1 (2017) <https://doi.org/10.1088/1755-1315/65/1/012050>

Handayani, I. Gusti Ayu Ketut Rachmi, Adi Sulistiyono, Tommy Leonard, Ardi Gunardi, and Fatma Ulfatun Najicha, 'Environmental Management Strategy in Mining Activities in Forest Area Accordance with the Based Justice in Indonesia', Journal of Legal, Ethical and Regulatory Issues, 21.2 (2018)

Handayani, I.G.A.K. Rachmi, Lego Karjoko, and Abdul Kadir Jaelani, 'Model Pelaksanaan Putusan Mahkamah Konstitusi Yang Eksekutabilitas Dalam Pengujian Peraturan Perundang-Undangan Di Indonesia', Bestuur, 7.1 (2019), 36-46 <https://jurnal.uns.ac.id/bestuur/article/view/42700>

Hanum, Willy Naresta, 'Setting of Earth Oil Management in Old Wells Based on the Principle Social Justice', Bestuur, 8.2 (2020), 70 <https://doi.org/10.20961/bestuur.v8i2.42789>

Husna, Cut Asmaul, 'Strategi Penguatan Pengelolaan Bersama Minyak Dan Gas Bumi Di Wilayah Laut Strengthened Strategy of Joint Management Oil and Gas in The', Jurnal Konstitusi, 15.1 (2018)

Husna TR, Cut Asmaul, 'Strategi Penguatan Pengelolaan Bersama Minyak Dan Gas Bumi Di Wilayah Laut', Jurnal Konstitusi, 15.1 (2018), 140 <https:// doi.org/10.31078/jk1517>

Ichlas, Rudy Iskandar, 'Questioning the Independence of Media Coverage in the 2019 Elections', Jurnal Bestuur, $8.1 \quad$ (2020) <https://doi.org/10.20961/ bestuur.42725>

Jaelani, A K, 'Politik Hukum Putusan Mahkamah Konstitusi Nomor 36/PUUX/2012 Tentang Pembubaran BP MIGAS: Upaya Mengembalikan Kedaulatan Negara Menuju ...', Jurnal Panggung Hukum, 1.1 (2015) $<$ https://www.aifis-

digilib.com/uploads/1/3/4/6/13465004/isi__3._politik_hukum_putusan_ mahkamah_konstitusi_(penulis_aqj).pdf $>$

Kajoko, L, Zaidah Nur Rosidah, and I.G.A.K. Rachmi Handayani, 'Refleksi Paradigma Ilmu Pengetahuan Bagi Pembangunan Hukum Pengadaan $\begin{array}{llll}\text { Tanah', } \quad \text { Bestuur, } & 7.1 & \text { (2019), } & 1-14\end{array}$ <https://jurnal.uns.ac.id/bestuur/article/view/42694>

Karjoko, Lego, 'Setting of Plantation Land Area Limitation Based on Social Function Principles of Land Cultivation Rights To Realize Social WelfarePromoting Plantation', Jurnal Dinamika Hukum, 17.1 (2017), 1 <https:// doi.org/10.20884/1.jdh.2017.17.1.606>

Kholil, Munawar, 'Waste to Energy Technology_ The Potenti...1 Waste in Indonesia _ Enhanced Reader.Pdf' 
Muryani, Eni, 'Sinergisitas Penegakan Hukum Pada Kasus Pertambangan Emas Tanpa Izin Di Kabupaten Banyumas, Jawa Tengah', Bestuur, 7.2 (2019), 19 <https:// doi.org/10.20961/ bestuur.v7i2.40437>

Najicha, Fatma Ulfatun, 'Water Availability in the Framework of Environmental Justice: Reconstruction of Municipal Waterworks (Pdam) Regulations', 20.4 (2019), 51-55

Najicha, Fatma Ulfatun, I Gusti Ayu Ketut Rachmi Handayani, and Hartiwiningsih, 'Legal Protection "Substantive Rights for Environmental Quality" on Environmental Law Against Human Rights in the Constitution in Indonesia', 140.Icleh (2020), 719-24 <https://doi.org/10.2991/aebmr.k.200513.136>

Nizammudin, Nizammudin, 'HAK MENGUASAI NEGARA DALAM SISTEM TATA KELOLA MINYAK DAN GAS BUMI: ANALISIS PUTUSAN MAHKAMAH KONSTITUSI NOMOR 36/PUU-X/2012 / The State Control Rights In Oil And Gas Management System: The Analysis Of Constitutional Decision No 36/PUU-X/2012', Jurnal Hukum Dan Peradilan, 5.3 (2016), 407 <https://doi.org/10.25216/jhp.5.3.2016.407-430>

Purba, Hasfarm D., Christia Meidiana, and Dimas W. Adrianto, 'Waste Management Scenario through Community Based Waste Bank: A Case Study of Kepanjen District, Malang Regency, Indonesia', International Journal of Environmental Science and Development, 5.2 (2014), 212-16 <https://doi.org/10.7763/ijesd.2014.v5.480>

Putuhena, M. Ilham F., 'POLITIK HUKUM PENGELOLAAN HULU MIGAS PASCA PUTUSAN MAHKAMAH KONSTITUSI (Politics of Law of Upstream Oil and Gas Management after the Constitutional Court Decision)', Jurnal Rechts Vinding, 4.2 (2015), 237-53 <http://rechtsvinding.bphn.go.id/artikel/ART 4 JRV 4.2 WATER.pdf>

Roestamy, Martin, 'Model Land Supply For Land Bank To House Application', Bestuur, 8.1 (2020), 27-39

Suartha, I Dewa Made, 'Criminal Policy Formulation on Regulation of Death Penalties for Criminal Actors', Journal of Morality and Legal Culture, 1.1 (2020), $12<$ https://doi.org/10.20961/jmail.v1i1.44743>

Waluyo, F. Ulfatun Najicha, and Sapto Hermawan, 'Law in the Globalization and Its Influence on Economic Development and Environmental Preservation Based on Pancasila and the Indonesian Constitution of $1945^{\prime}$, 358.Icglow (2019), 317-21 <https://doi.org/10.2991/icglow-19.2019.78> 